\title{
Margaret Archer and a morphogenetic take on strategy
}

Abstract

The morphogenetic framework developed by the social theorist Margaret Archer is outlined in order to suggest what it might bring to the study of strategy. It is contrasted to practice-based approaches, notably those associated with the work of Richard Whittington and the domain of strategy as practice. Archer's work provides a non-deterministic approach which enables the situating of moments of strategic practice in a wider context. Its stress on agential reflexivity opens up interesting lines of inquiry, not least on the language of strategizing facilitated and encouraged by the multinational corporation. The approach needs to pay more attention to practices, notably organizational routines, but it offers rich resources to the student of organizational strategy.

Keywords

Margaret Archer; critical realism; strategy; structure; agency; reflexivity

\section{Introduction}

Margaret Archer is a major figure in the world of social theory and sociology. Starting as a sociologist of education she has developed a distinctive approach to the study of society through her engagement with the philosophical tradition of critical realism. Through a critique of how these ideas have been applied in the social domain, she has progressively developed and refined a view of what she terms the 'morphogenesis' of society. This view, recognising that society is activity dependent and is changed and reproduced through the activities of human agents who operate in conditions not of their choosing, has had increasing traction in many domains of 
inquiry, not least in the field of organization studies. Her body of work is extensive and complex. Strategy as understood in business and management is not one of its concerns. However, I want to show that her work offers rich resources for the investigation and critique of strategy, both for its impact within organizations and on broader society.

Let me start this consideration of what her work might have to offer students of strategy with a text from one of the more influential recent writers on the topic. 'Structuration theory,' writes Richard Whittington in a consideration of 'strategy as practice', 'has real purchase where circumstances are plural and fluid, where firms enjoy oligopolistic powers of discretion or where middle managers or others are confident and knowledgeable enough to exploit their powers' (Whittington 2010: 124). He contrasts this suitability to 'the more fatalistic theoretical rivals such as Bourdieu and Bhaskar' (Whittington 2010: 124). I am going to argue that this is a misrepresentation of, at least, the work of Roy Bhaskar, the major figure in the philosophical tradition of critical realism. In this way, I use the work of Whittington as something of a foil throughout this article, as on closer examination his own relation to critical realism proves to be a little more complex. My aim is to clarify some aspects of critical realism and its relation to social theory, which will necessitate the correction of a number of misrepresentations. I seek to show that it is misleading to refer to a critical realist theory of any phenomenon, misrepresenting as this does its self-declared role as conceptual under-labourer for substantive theorisation. This leads to a consideration of Archer's work, often seen, as in the lens employed by Whittington, as a form of structuralism. I argue that this is to fail to pay attention to her full body of work, which rather shows increasing attention over time to questions of reflexivity. I draw on some aspects of her work, and that of Whittington, to suggest 
how they might be brought to bear on organizational strategy. This then frames a consideration of some challenges and opportunities under the headings of practice, history, language, and reflexivity. For each I suggest where proponents of critical realism need to refine their concepts, but also what the tradition has to offer.

\section{Critical realism}

Starting with the undoubted achievements of science as manifest in not only successful experiments but also in technological artefacts, Roy Bhaskar (1979) posed the question (in my paraphrase), 'what must the world be like for scientific practice to be possible?' From this starting position he suggested the potential of a revived realism, one which posited the existence of a world independent of our conceptions of it, but only partially and imperfectly observable through our theoretical conceptions. This is a realism not to be confused with the naïve realism of common sense experience or the satisfaction with superficial correlations of scientific realism. Rather, it is a realism which proposes an ontology of depth which leads to three distinctive commitments, summarised as ontological boldness, epistemological relativism and judgmental rationality (for accessible summaries of, and introductions to, critical realism and Bhaskar's early work see Collier, 1994 ; Sayer, 1992, 2000; Danermark et al, 2002; Edwards, O’Mahoney and Vincent, 2014). The boldness of ontology is in the claim to a mind-independent reality, one which exists regardless of our knowledge of it and can only be apprehended by our fallible conceptualisations of it. This reality is conceived of as stratified into the real, the actual and the empirical. The real is not that which can be sensed but rather the mechanisms that produce the sensations that can be experienced. At the level of the observable is the empirical, but what can be observed may be misleading. Beyond these surface 
appearances is the domain of the actual, which is the playing out of the consequences of the real, the mechanisms that set the actual in motion. It is the search for these mechanisms, argues Bhaskar, which animates the scientific enterprise. Thus it is necessary to place ontology, the nature of the world, at the forefront of our investigations. The world is not limited to our conceptions of it, because these can be fallible when put to the test of the world. To confuse epistemology with ontology, argues Bhaskar, is to commit the 'epistemic fallacy', to conflate reality with our imperfect understanding of it. From this it follows that the way we understand particular aspects of the world depends on our understanding of its nature. Our methods of inquiry, that is, need to be configured to address the particular nature of that aspect of the world that we are interested in, hence the adherence to epistemological relativism. That is, our methods of inquiry are relative to the phenomena we are seeking to understand. Finally, this tradition argues that there are ways of adjudicating between different knowledge claims, that some ways of understanding the world are more adequate than others. In part, this colours the attaching of the term 'critical' to realism, although this has a number of meanings. In one sense, it seeks to firmly demarcate this understanding of realism from other, cruder, appellations. However, it also indicates a certain emancipatory intent, whereby better understanding of the world is a necessary, if not sufficient, part of seeking to change that world to promote human flourishing (for debates about this claim from within the tradition, see Frauley and Pearce, 2007).

That last statement indicates a shift from the natural to the social world, a shift that brings with it certain complications. The key question is that of the double hermeneutic (Outhwaite, 1987). That is, critical realism, in line with other traditions, recognises the inescapable role of interpretation in seeking to understand the world. 
There can be no direct access to the nature of the world, with a mirror like reflection of its features. However, in studying the social world the objects of our study also have interpretive powers of their own. In this way the interpretations as well as their products are a vital part of our studies. Bhaskar sought, through an engagement with, in particular, the work of Giddens, to translate his ideas, developed from the study of natural science, to the social world, through the formulation of his Transformational Model of Social Action (TMSA). However, this is not the only social theory compatible with his broader ideas and, indeed, is not the most influential. This raises a very important question, that of the relation of critical realism to substantive social theory.

Critical realism sees itself as a philosophical tradition whose contribution to social theory (and to theorising about substantive domains tout court) is as a conceptual 'under labourer'. That means that it is strictly speaking misleading to label any substantive theory of any domain as 'critical realist', albeit that such labelling is widely applied. It is misleading in particular because the basic tenets of critical realism can be compatible with different substantive theories. We can see this in the social domain with the contrast between the work of Margaret Archer and Rob Stones. Both share a common commitment to Bhaskar's key formulations but have sharply contrasting approaches to the work of Anthony Giddens and his structuration theory. Stones (2005) seeks to use some of the resources of realism to rescue and revive structuration theory in the guise of what he terms 'strong structuration; by contrast Archer (1995) engages in a sharp critique of what she terms Giddens' 'conflation' of agency and structure to comprehensively reject structuration theory.

We could cite other social theorists, such as Derek Layder (1990) in the field of sociology, Tony Lawson (2003) in economics and Sven Modell in accounting (2016), 
who also draw on Bhaskar to present different inflections. This is important to bear in mind, for there is not a homogeneous critical realist 'line' on the nature of the social world, with many sharp debates amongst those who share the same basic commitments. It also means that critical realism may be compatible with, and indeed a useful development of, other theoretical efforts. In the sphere of organizational theory one such relationship which might be particularly promising is that with the 'institutional logics' formulated by Friedland and Alford (1991). These possibilities are discussed further below. The reason for focussing in this article on Archer's work is both that it is the most thoroughly worked through of these perspectives and that it is the one that has been the most broadly influential. It is also one which, when considered in full, answers concerns about 'fatalism'.

\section{Archer and morphogenesis}

It is useful to outline briefly the development of Archer's work, because it reinforces the point made above about the connection between philosophy and substantive theory. Archer worked in the field of the sociology of education, drawing on sociological and systems theory to present an extensive account of the social origins of educational systems (Archer, 1979). Covering a period of some 600 years, this presented a comparative account of changes in educational systems in four nation states - the UK, Denmark, Russia and France - selected because of their differing characteristics. She suggested that traditions of political authority manifest in either relatively centralised or decentralised polities were a crucial factor in the fate of otherwise broadly similar patterns of educational reform. Her work was, that is, already that of an established sociologist which trailed many of the aspects of her later work before her engagement with ideas drawn from critical realism. It is also 
important to note that her first substantive work arising from this engagement was not concerned with structure but rather with the status of culture (Archer 1996). This was later revised to be aligned with her account of the relationship between structure and agency, but it is indicative of rather more complexity in her work than is often recognized. The next book on Realist social theory: the morphogenetic approach is the best known and most influential of her work, but this in itself is problematic (Archer, 1995). The problem comes when we stop at this book and its concerns, seeing it as a terminal point in itself rather than simply setting the stage for a project of exploration of the crucial role of reflexivity as the key mediating mechanism between agency and structure. We will touch on some of this broader project, but it necessary first of all to consider morphogenesis a little further.

The term morphogenesis derives from Greek terms for change and agency. As Archer explains, 'The 'morpho' element is an acknowledgment that society has no pre-set form or preferred state: the 'genetic' part is a recognition that it takes its shape from, and is formed by, agents, originating from the intended and unintended consequences of their activities' (Archer, 1995: 5). It is contrasted to 'morphostasis', which is a recognition that actions in the social world often (indeed, perhaps usually) reproduce and confirm existing social arrangements. The focus on the relationship between structure and agency means that this is seen as a dynamic approach in which history needs to be fully considered. Archer provides a summary:

every morphogenetic cycle distinguishes three broad analytical phases consisting of (a) a given structure (a complex set of relations between parts), which conditions but does not determine (b), social interaction. Here, (b) also arises in part from action orientations unconditioned by social organization but emanating from current agents, and in turn leads to (c), 
structural elaboration or modification - that is, to a change in the relations between parts where morphogenesis rather than morphostasis ensued. (Archer, 1995: 91; emphasis in original)

Take in figure one about here

Structure here also includes, in the fuller scheme, a relationship to culture. Here Archer draws on ideas of emergence from critical realism together with other influences, notably Popper's ideas of three worlds of ideas, to posit the status of ideas, once emergent from human activity, as entities with causal powers in their own right, notably in relations of contradiction with other sets of ideas. As with structural components, such as organisations which, once emergent from human activity cannot be reduced to the activities of current actors (although dependent on those activities), ideas form part of the situational logics which shape and condition activity. They do so not in any deterministic way but by shaping the universe of possibilities which agents face. This is stronger than a simple matter of choice, for these situational logics make powerful suggestions about appropriate courses of action. This is particularly the case when these options seem so obvious as to be 'natural', to have concealed the social conditions of their own production. However, while in many cases actors will choose to act in ways consistent with the avenues suggested by structural and cultural logics, this is in no way predetermined. If they are prepared to pay the opportunity costs then they can choose to take alternative courses, opening the possibilities for change. 
What this formulation suggests is the importance of history, with the injunction from Archer being the need to construct what she terms 'analytical histories of emergence'. These she suggests

can never ever be grand precisely because the imperative to narrate derives from recognizing the intervention of contingency and the need to examine its effects on the exercise or suspension of the generative powers in question since outcomes will vary accordingly but unpredictably. On the other hand, analytical narratives are obviously distinct from any version of historical narration tout court, for although social realists in general have no difficulty in accepting the strong likelihood of uniqueness at the level of events, the endorsement of real but unobservable generative mechanisms directs analysis towards the interplay between the real, the actual and the empirical to explain precise outcomes (Archer, 1995: 343).

The implications of these injunctions for the study of strategy will be considered in the next section, but first it is important to recognise that laying out these situational logics is only the first part of the account. What Archer has explored in considerable detail is her contention that agential reflexivity is the key mechanism linking agency and structure (Archer, 2000, 2003, 2007, 2012). Drawing on a wide variety of sources, but especially the American pragmatist tradition, she has argued that reflexivity under some form is a defining characteristic of what it is to be human.

Reflexivity on this account is related to the monitoring of ongoing projects, of reflection on how such projects are to be fulfilled with the view of satisfying valueladen objectives. These objectives grossly exceed the narrow focus on utility maximisation by adherents of rational choice theory. All humans engage in reflexive 
activity, but not all that activity is of the same character. Archer (2003) identifies three prime modes of reflexivity and a fourth mode which is marked by failure. All actors, she argues, exhibit these modes in different combinations, but often with a dominant mode which in turn can be related to broader cultural and structural conditions.

Conversational reflexivity is where actors need others to complete their reflection through shared conversations which also often imply shared background assumptions. This is related by Archer to more traditional settings marked by 'contextual continuities' of both time and space. She suggests that this is the world of the classic community studies, and one which is under threat from the mode of reflexivity conditioned by the relentless mobility of a globalised world, in which a key actor is the multinational corporation (Archer 2007). Techniques of 'rational' decision making in conditions of contextual discontinuity shape the mode of 'autonomous reflexivity'. This is the world of the rational decision maker, who weights up costs and benefits at a distance from others. It is a dominant mode of advanced societies since the 1960s, but it is in turn challenged by what she terms 'meta reflexivity'. This is where actors not only reflect on the success of their projects but also on their forms of reflexivity. Such reflexives, argues Archer, are society's critics and their numbers have been swollen by the broader proliferation of ideational alternatives which throw into question older certainties. The situational logic of competition, that is, has been replaced by one of pluralism (Archer, 2012).

The relationship, and the adequacy, of this contention with relation to strategizing more generally will be considered later, but to complete the coverage it is necessary to recognise what Archer terms 'fractured reflexives', those who through, whatever cause, are unable to formulate and monitor projects of ultimate concern. These are 
society's victims, doomed to be shaped by forces external to them. This necessarily brief summary cannot do justice to the richness and complexity of ideas developed in six books. It might indicate something of the complexity that might be involved in applying them to a consideration of strategy. However, it should point to the resources that are available; in the next section we can see how they might be related to the study of strategy.

\section{Morphogenesis and strategy}

It is important to note both that Archer's morphogenetic framework was developed in the domain of social theory and that she sees it applicable to a range of social questions. While her discussions are generally at a high level of abstraction and treat issues across large sweeps of time, she suggests that the approach can help give analytical purchase to both macro and micro topics, being 'a tool of the working social analyst which gives explanatory purchase on substantive social problems, through supplying the terms or framework for their investigation' (Archer, 1995: 123). It follows that this perspective rejects the suggestion by Whittington that particular social theories are more applicable to particular conjunctures. Rather the claim is that the formulation of structure conditioning agency is both non-deterministic and applicable to periods of both social stasis and change - hence Archer's outlining of the conditions that might lead to either reproduction of the existing order morphostasis - or to transformation - morphogenesis.

Organizations and organization theory do not figure prominently in her formulations, although, as noted above, her more recent work has engaged with the impact of the multinational corporation on contemporary society. It follows therefore that it has been down to others to explore the implications for the study of organizations in a steady flow of work, some of which will be drawn upon in what follows (Elder-Vass, 
2012; Edwards, O'Mahoney and Vincent, 2014). It is also worth noting that critical realism more broadly sees its project as being a conceptual 'under labourer' for more substantive inquiries. We can see Archer's work in helping provide some conceptual clarity about, for example, the relationship of reflexivity to situational logics, but that work still needs to be brought into engagement with existing domains of inquiry and theories. That is one reason for using strategy as practice as the focus for the following discussion.

Before looking at that in detail, however, it is worth considering one candidate for a closer engagement between Archer's morphogenesis and an influential organizational theory. This is the institutional logics perspective, already mentioned above and suggested as a potential resource by Modell (2015) in his discussion of the prospects for accounting research of critical realism. As originally conceptualised by Friedland and Alford (1991), institutional logics were seen to be combinations of material and symbolic practices shaping meaning, action and identities in distinct institutional orders. These orders, such as religion, the market and the state, had relations of contradiction and complementarity with each other, but operated in a non-deterministic fashion in particular conjunctures of time and space. However, the version engaged with by Modell (2015), that developed by Thornton, Occasio and Lounsbury (2012), has been criticized by many, not least by Friedland (2012) himself, for reducing logics to a matter of variables. By contrast, Friedland has himself developed an alternative conception of institutional logics which holds out much more promise for a fruitful encounter with Archer's work (Friedland, 2009, 2014). Drawing on the Aristotelian notion of substance, he suggests that institutional logics consist of substance and practices. These substances, values like 'accountability', are real in the sense that they have impacts in society, giving 
meaning to practices, but they recede from capture. Rather, they are immanent in practices, practices which are animated by belief in the substance, in a complex and recursive whole.

This offers promise for an Archerian approach for a number of reasons. The notion that the real is not that which is visible but that which animates the visible is consistent with the broader ontological claims of critical realism. The conceptualisation of society as composed of multiple interacting but relatively autonomous institutional orders is consistent with Archer's critique of structuralist, especially Marxist, variants of social theory. And the notion of logics which suggest courses of action, especially when that action seems 'natural' and with the grain, but does not determine that action, leaving space for agential reflexivity, is consistent with her focus on 'situational logics'. However, the focus on practices perhaps suggests a need to return to her formulations.

\subsection{Practices}

Archer is uncomfortable with practice-based theories, especially those associated with Giddens and Bourdieu. She sees such approaches as guilty of 'central conflationism', of collapsing the relationship between structure and agency into the category of practice (Archer, 1995: 101). It is not that she is not conscious of the importance of practical engagement with the world. Practical knowledge is a key term for Archer, in accord with her focus on embodied encounters with the world (Archer, 2000). For Archer, our key engagements with the world are in what she terms the natural, the practical and the social orders. The practical order is concerned with our embodied accomplishment of tasks. This distinction of orders means that practice in the social world is perhaps a rather neglected category in the morphogenetic canon. Debates, touched on below, about the formulation of 
reflexivity by Archer have turned on the concept of habit. Developed in particular in the context of Bourdieu's notion of 'habitus', this has been used by critics to suggest that Archer has underplayed the extent to which habit plays an important role in conditioning reflexivity (Archer, 2012). The problem with this debate, on both sides, is that it has focused on habit as a property of persons. By contrast, if we reach back into Bhaskar's work, we find that in his TMSA he used the term 'position-practices' to capture the full range of what was involved by sociological terms such as 'role', a usage which in turn influenced Giddens (Bhaskar 1979; Giddens, 1984). By this, Bhaskar is noting that specific practices are attached to particular 'slots' in social relations. Thus, the social positions given by the roles 'landlord' and 'tenant' necessarily involve practices such as the payment of rent. The content of such practices of course varies given broader contexts but this is a matter of empirical investigation. For our purpose, this shifts our attention from 'practice' to 'practices'.

One way of engaging with practices in the specifically organizational context is through a consideration of routines. From an Archerian perspective, much of the existing literature has an excessive focus on the performance of routines, failing to take full account of the structuring of routines by their location in broader structural and cultural contexts (Mutch, 2013). This neglects the degree to which routines are designed in the context of broader imperatives, focussing instead on the way in which performances are never identical. Increasingly, routines are inscribed into information and communication technology, sedimenting in relatively enduring fashion particular notions of what is considered 'best practice'. Indeed, many software solutions are based on precisely this capacity to codify and solidify routines (Mutch, 2010). Of course, there will be degrees of resistance and adaptation, but in order to understand these some sense of the situational logics that routines present 
is invaluable. In addition, it is in encountering such routines that organizational actors confront the entailments of culture and structure, rather than at some more abstract level. Such a focus on routines would then be congruent with elements of strategy as practice, with its focus on how agents encounter strategizing in particular spaces utilizing particular artefacts.

There is no principled reason, that is, why morphogenesis cannot be applied to the notion of strategy as practice. Indeed, this has been powerfully demonstrated by Andrea Herepath (2014), in her morphogenetic examination of the practices engaged in within the health service, connecting a detailed insider account of practices with the broader features of the wider social and cultural context, with particular focus on the constraining and enabling features presented by the history of health initiatives in Wales. However, the very richness that is achieved indicates some problems with this approach. One is that it is developed at considerable length. The second is that it is dependent on researcher access, access which is also conditioned by the availability and understanding of a rich conceptual apparatus. This means that while one can suggest that a morphogenetic approach offers rich resources for those who seek to connect practices to their broader context, the feasibility of the approach given the wider constraints in turn of the research context might make this a counsel of perfection.

\subsection{History}

Given these caveats, a morphogenetic approach also connects with the calls for more attention to history in organizational analysis (Bucheli and Wadwhani, 2014). As we have seen, Archer calls for analytical narratives of emergence. Rowlinson, Hassard and Decker (2014), in their consideration of varieties of historical approaches in organization theory, link the notion of analytical narratives with 
positivism, but Archer's work suggests that we need to nuance this claim. The very fact of providing a narrative, with its recognition of contingency, undermines the links with positivism. However, the commitment to analytical frameworks, with careful specification of key concepts, tackles the problem of the unsurfaced assumptions that often characterize purely narrative accounts. In particular, it stresses the need to identify long term patterns of ideas and activities that provide the context for actions observable in the present. An intriguing echo of these debates can be found in Whittington's work that preceded the formulation of strategy as practice.

Whittington's Corporate strategies in recession and recovery: social structure and strategic choice, published in 1989, sought to combine Bhaskar's ontology with aspects of Giddens' structuration theory to argue that strategic decision makers had margins of discretion within the logics that broader structural factors gave them. These strategic choices were exercised within a 'narrow range of social logics', but these were not simply constraints; they could also facilitate action. This had two implications for the broader nature of research into corporate strategies.

Fundamental is an analysis of strategic conduct - an attempt to understand how the decision-makers see the world and what they seek from it. However, this understanding must be tempered by a more detached analysis. Institutional analysis should be directed at amplifying actors' own accounts by establishing the structures upon which their actions both depended and worked (Whittington 1989: 118).

This suggested further that analysis should proceed by comparison between firms in the same competitive environment, seeking to identify differing strategic responses. In suggesting this, Whittington deliberately set his approach against the 
'contextualist' school. The foremost example of such an approach was Andrew Pettigrew's (1985) study of organization development at the chemical company ICI. Here contextualism was said to combine 'both multilevel or vertical analysis, and processual or horizontal analysis' Pettigrew, 1985: 37). This was developed by explicit reference to Giddens' structuration theory, although this was never explored in any great depth. However, for Whittington, the peril of the contextualist approach was that, 'the deeper they have burrowed and the greater the empathy of their accounts, the more their concerns have become confined to those of the companies themselves' (Whittington, 1989: 68). This meant both that these accounts became over-dependent on the analyses of the actors themselves and that the broader strategic context was not properly specified. This suggests the importance of comparative work of the type later essayed by Whittington and Mayer (2000) in their exploration of the organizational forms adopted in three economies: France, Germany and the UK.

In its espousal of 'a modestly generalizing social science of management', this has much in common with many of the features of a morphogenetic approach, albeit that this account is now shorn of any references to realism, critical or otherwise (Whittington and Mayer, 2000: 4). The adoption of a form of modest quantification, one suitably aware of the limitations of the evidence, is also in accord with the place accorded to such techniques by critical realists. The conclusion, of a secular trend towards the adoption of the multi-divisional form, subject to the mediating influences of national traditions, is suggestive for our later discussion of reflexivity. 'To engage in diversification, and to adopt the multidivisional structure,' argue Whittington and Meyer, 'is to trust in the value of abstract, generalizable knowledge. The success of the diversified multidivisional represents a continuing endorsement of the possibility 
of such rational abstraction' (Whittington and Mayer, 2000: 224). Such an approach deliberately brackets contextualised practices in order to carry out its analysis, but it is clear that its conclusions have implications for such practices.

What this account suggests is the importance of history for the study of strategy in two senses. One is the use of history to, in Friedland and Alford's (1991) phrase, 'bring society back in'. That is, the short run of strategic choices made in seeming freedom from other influences might turn out in a longer perspective to have been shaped by more enduring factors. Thus, Archer's (1979) study of educational systems where, after all, what we might term strategic decisions were taken about the shape of schooling, points to enduring facets of societal contexts in which similar decisions met with different fates. The second is the need to take into account organizational histories beyond the specification of immediate 'context'. In the case of UK brewing, where a secular trend towards a retailing, as opposed to a production, logic in the major strategic responses of major companies in the period 1950-1999 can be traced (Mutch, 2006a), it is illuminating to turn back to the midnineteenth century, where early experiments with retailing were found in the experience of a major component of one of these companies, Allied Breweries (Mutch, 2006b, 2006c). Allied Breweries underwent a very hesitant turn to retailing, which can in part be attributed to its early experience with the management of public houses. These gave it a rather top-down and inflexible approach to retailing. By contrast, another major company, Whitbread, embraced leisure retailing in wholehearted fashion. We can see this divergence as a different reading of the competitive opportunities, but it was one shaped by organizational history. This divergence can also be traced in the language used to represent the shift in logics by each company. 


\subsection{Language}

Language is often seen as the Achilles heel of the full range of realisms, on the basis that language is constitutive of (social) reality, not just a representation of the world. This is ironic in the case of critical realism, where adherents in the domain of economics have argued robustly for the necessarily metaphorical nature of language (Lewis, 1999). The work on metaphor by Lakoff and Johnson (1980), with its derivation from embodied encounters with the world, is thoroughly consistent with such a position. However, it would be fair to recognise that Archer tends to downplay the importance of language in her discussions. In an account that draws on detailed work in the ontogeny of human development she points to the primacy of nonlinguistic experience of the world in shaping awareness of the self, long before the conceptual apparatus, expressed in language, is available to express such awareness (Archer, 2000). Her work on the 'internal conversation' also might be thought to rather neglect work in sociolinguistics (Mutch, 2004). However, as in all fields of human endeavour, there is an intellectual division of labour and others working in the same tradition have paid considerable importance to language. In particular, Norman Fairclough who, with influences from Foucault and others, has developed a particular form of 'Critical Discourse Analysis', has recognised its compatibility with the broad tenets of critical realism (Fairclough, 2005). This was confirmed in a collaborative article with Bob Jessop and Andrew Sayer which suggested the need to expand the scope to look at semiosis (Fairclough, Jessop and Sayer, 2002).

There is no shortage, that is, of those working in the critical realist tradition taking language seriously. One example which draws very directly on Fairclough's work in a consideration of broader strategic discourses is the consideration by Paul Thompson 
and Bill Harley (2012) of the competing discourses of 'the knowledge economy' and 'shareholder value'. Although given the comments above I would quibble a little with the claim that this is a 'critical realist analysis', this shows the value of using ideas derived from this tradition to interrogate key discourses, especially by setting them against their broader social context. Doing so indicates that for all the widespread discussion of the importance of the knowledge economy, the logic of shareholder value has actually dominated the strategic choices of organizations. This indicates not only that critical realism has resources to tackle questions of language, but that it enables such questions to be related to broader forces. It is fair to observe that such analyses consider discursive statements at a high level of generality, often resting on published statements. However, there is no principled reason why the detailed methods of conversation analysis should not have their place. As noted above, work in the critical realist tradition seeks to place the methods used firmly in the context of the nature of the phenomenon under investigation. It will be seen that Archer's perspective is one in which actors do not simply construct society through their immediate interactions, but produce or reproduce contexts which were produced by actors no longer present.

\subsection{Reflexivity}

Perhaps the most intriguing area where social theory in this tradition and the study of strategy might be mutually enriching is in Archer's consideration of reflexivity. Her suggestion is that the rise of autonomous reflexivity, that is, where actors complete their own evaluations of their projects in relative autonomy from the contributions of others is fostered by the twin developments of information technology and the multinational corporation. These foster decision making techniques which emphasis the formal and the codified. In this one might see some support in the contentions of 
Whittington and Meyer noted above. That is, while the failures and problems of such techniques are often the focus of much academic attention, they are nonetheless successful. To take one example, much of the literature on information systems such as Enterprise Resource Planning systems (notably the product SAP) focuses on their implementation and reports on the initial problems that they face. However, this focus on failure could be seen to be an artefact of research design, as more longitudinal studies tend to suggest that, however imperfectly, such systems do perform the role of enabling multinational companies to run their affairs (Pollock and Williams, 2009). That such systems may have unintended consequences of lowering workforce morale and customer satisfaction is an important consideration, but what is important for our consideration of reflexivity is that their widespread use conditions particular 'thought styles', ones which might be thought to further foster reflexive autonomy (Mutch, 2010).

As a counterweight, Archer suggests that in reaction to this the broader cultural and structural features of early twenty-first centuries suggest a climate conducive to greater meta reflexivity. This is because of wider participation in higher education and the explosion of ideational resources fostered by the growth of information technologies outside the boundaries of the corporation. However, in counter to this, and this is where the study of strategy might inform social theory, we could point to the spread of the language of strategizing. That is, work on strategy as practice has shown how practices of strategy making have spread beyond the ranks of strategic planning units to involve wider groups. Even if the actual purchase of such groups on the formulation of strategy is weak, the language of strategy becomes more widely deployed. In this way one could argue that, carried by particular tools and techniques, strategizing in its wider sense colonizes ever wider spheres of activity. 
The extent of this is an open question, but it suggests an agenda for those working with morphogenesis in the study of strategy. This is to combine the already strong framework that Archer has supplied with considerations of language, practice and reflexivity.

\section{Conclusion}

It follows from this review that there are two objections to be raised to Whittington's remarks that were cited at the beginning of the article, at least as they relate to the most influential refiner of Bhaskar's ideas as applied to the social domain. One is that Archer's formulations are strongly resistant to any notions of determinism, be they structural, linguistic or, indeed, genetic. She pays full attention to the cultural and social circumstances in which agents find themselves involuntarily placed, to be sure, but her emphasis on agential reflexivity as the key mechanism linking those circumstances to action undercuts any claims of determinism. Those circumstances provide, certainly, strong situational logics, logics which might be all the more powerful for being unremarked, but agents always have the chance to do differently - provided always that they are prepared to pay the opportunity costs of so doing. This suggests that for strategy that the focus is on strategic choice, but choice conditioned by particular conjunctions. The task for analysis is to specify such contexts adequately. It has been a contention of this article that this means paying more attention to history than is typically the case. While rich descriptions of practice are often illuminating, they get their full power from being placed in the cultural and structural circumstances of their performance. 
As noted above, one potential resource for the incorporation of these conditioning elements into the study of strategy is the burgeoning literature on institutional logics. This facilitates the consideration of a broader range of influences on strategy, drawing to our attention the often taken-for-granted conditions of possibility that shape action. For example, national traditions of what it means to manage are often deeply embedded, as in the long-standing concern by British managers with management as leadership as contrasted to, for example, German emphases on technical excellence. In turn, such contrasts can be set in the context of enduring differences in religion and the law that Friedland's formulations draw to our attention (Mutch, 2006d)

The second objection to Whittington's formulation is the notion that certain theories are better adjusted to particular circumstances. By contrast, the claim for Archer's approach is that it can be applied to any situation in social life, whether that be a detailed examination of local strategic practice or the unfolding of relationships between organizations at a societal level. As she writes at the conclusion of her 1995 book

Other investigators of entirely different problem areas will find nothing here which will enable them to dispense with doing their own footwork (though hopefully it indicates a useful path to tread), for this is the reason why throughout this book social analysis has been held to entail practical social theorizing. (Archer, 1995: 327-8; emphasis in original).

This means that the continuing challenge that Archer leaves to us in the field of strategy is to engage with existing approaches, such as strategy as practice, with a 
view to reformulating and developing their valuable insights within the framework that she provides.

\section{References}

Archer, Margaret. (1979) Social origins of educational systems, London: Sage.

Archer, Margaret. (1995) Realist social theory: the morphogenetic approach, Cambridge: Cambridge University Press.

Archer, Margaret. (1996) Culture and agency: the place of culture in social theory, Cambridge: Cambridge University Press.

Archer, Margaret. (2000) Being human: the problem of agency, Cambridge: Cambridge University Press.

Archer, Margaret. (2003) Structure, agency and the internal conversation, Cambridge: Cambridge University Press.

Archer, Margaret (Ed.). (2010) Conversations about reflexivity, Abingdon: Routledge.

Bhaskar, Roy. (1979) The Possibility of naturalism, Hemel Hempstead: Harvester.

Bucheli, Marcelo and Wadhwani, R. Daniel, (2014) Organizations in time: history, theory, methods, Oxford: Oxford University Press.

Collier, Andrew. (1994) Critical realism: an introduction to the philosophy of Roy Bhaskar, London: Verso.

Danermark, Berth. Ekstrom,Mats, Jakobsen Liselotte, and Karlsson Jan (2002) Explaining society: critical realism in the social sciences, London: Routledge. 
Edwards, Paul, O'Mahoney,Joe, and Vincent Steve, (2014) Studying organizations using critical realism: a practical guide, Oxford: Oxford University Press.

Elder-Vass, Dave. (2010) The causal power of social structures, Cambridge: Cambridge University Press.

Fairclough, Norman. Jessop,Bob, and Sayer Andrew, (2002) Critical realism and semiosis, J. of Critical Realism, 5(1), 2-10.

Fairclough, Norman. (2005) 'Peripheral vision: discourse analysis in organization studies: the case for critical realism', Organization Stud., 26, 915-939.

Frauley, Jon and Pearce,Frank, (Eds) (2007) Critical realism and the social sciences: heterodox elaborations, Toronto: University of Toronto.

Friedland, Roger and Alford,Robert, (1991) 'Bringing society back in: symbols, practices, and institutional contradictions', in W. Powell and P. DiMaggio (eds) The new institutionalism in organizational analysis, Chicago: University of Chicago Press, 232-266.

Friedland, Roger. (2009) 'Institution, practice and ontology: towards a religious sociology', Res. in the Soc. of Organzations, 27 45-83.

Friedland, Roger. (2012) 'Book review: Patricia H. Thornton, William Occasio and Michael Lounsbury 2012 The institutional logics perspective: a new approach to culture, structure, and process', M@n@gement, 15(5), 582-595.

Friedland, Roger. (2014) 'Divine institution: Max Weber's value spheres and institutional theory', Res. in the Soc. of Organzations, 41 217-258. 
Giddens, Anthony. (1984) The constitution of society: outline of the theory of structuration, Cambridge: Polity.

Herepath, Andrea. (2010) Strategy as practice from macro to micro, Unpublished PhD thesis: Cardiff University.

Herepath, Andrea (2014) In the loop: a realist approach to structure and agency in the practice of strategy, Organization Stud., 35 (6), 857-879.

Lakoff, George. and Johnson,Mark, (1980) Metaphors we live by, Chicago:

University of Chicago Press.

Lawson, Tony. (2003) Reorienting economics, London: Routledge.

Layder, Derek. (1990) The realist image in social science, London: Macmillan.

Lewis, Paul. (1999) Metaphor and critical realism, in S. Fleetwood (Ed.) Critical realism in economics: development and debate, London: Routledge, 83-101.

Modell, Sven. (2015) 'Making institutional accounting research critical: dead end or new beginning?' Acctg, Auditing \& Accountability Jl., 28(5), 773-808.

Modell, Sven. (2016) 'Critical realist accounting research: in search of its emancipatory potential', Critical Perspectives in Accounting, in press.

Mutch, Alistair. (2004) 'Constraints on the internal conversation: Margaret Archer and the structural shaping of thought', Jl. for the Theory of Soc. Behav., 34(4), 429-445.

Mutch, Alistair. (2006a) Strategic and organizational change: from production to retailing in UK brewing 1950-1990, London: Routledge. 
Mutch, Alistair. (2006b) 'Allied Breweries and the development of the area manager, 1950-1984', Enterprise and Society, 7(2), 353-379.

Mutch, Alistair. (2006c) 'Public houses as multiple retailing: Peter Walker \& Son 1846-1914', Business History, 48(1), 1-19.

Mutch, Alistair. (2006d) 'The institutional shaping of management: in the tracks of English individualism', Management \& Organization History, 1(3), 251-271

Mutch, Alistair. (2010) Organizational use of information and communication technology and its impact on reflexivity, in M. Archer (Ed.) Conversations about Reflexivity, London: Routledge, 243-258.

Mutch, Alistair. (2013) 'All routine and repetition: the routinization of organizational life?', International Association for Critical Realism conference plenary address, Nottingham: https://www.academia.edu/5535719/All routine and repetition [28 April 2014]

Mutch, Alistair. (2014) 'History and documents in critical realism', in Paul Edwards, Joe O'Mahoney and Steve Vincent (eds) Studying organizations using critical realism: a practical guide, Oxford: Oxford University Press.

Outhwaite, William. (1987) New philosophies of social science: realism, hermeneutics and critical theory, London: Macmillan.

Pettigrew, Andrew. (1985) The awakening giant: continuity and change in ICl, Oxford: Blackwell.

Pollock Neil and Williams, Robin.( 2009). Software and organisations: the biography of the enterprise-wide system or how SAP conquered the world, London: Routledge. 
Rowlinson, Michael, Hassard, John and Decker, Stephanie. (2014) 'Research strategies for organizational history : a dialogue between historical theory and organization theory', Acad. of Mangt Rev., 39(3) 250-274.

Sayer, Andrew. (1992) Method in social science: a realist approach, London: Routledge.

Sayer, Andrew. (2000) Realism and social science, London: Sage.

Stones, Rob. (2005) Structuration theory, Basingstoke: Palgrave Macmillan.

Thompson, Paul. and Harley,Bill, (2012) Beneath the radar? a critical realist analysis of 'the knowledge economy' and 'shareholder value' as competing discourses, Organization Stud., 33(10), 1363-1381.

Thornton, Patricia, Occasio, William, and Lounsbury, Michael. (2012) The institutional logics perspective: a new approach to culture, structure, and process, Oxford: Oxford University Press.

Whittington, Richard. (1989) Corporate strategies in recession and recovery: social structure and strategic choice, London: Unwin Hyman.

Whittington, Richard. and Mayer,Michael, (2000) The European corporation: strategy, structure and social science, Oxford: Oxford University Press.

Whittington, Richard. (2010) Giddens, structuration theory and strategy as practice, in D. Golsorkhi, L. Rouleau, D. Seidl, and E. Vaara. (Eds) Cambridge handbook of strategy as practice, Cambridge: Cambridge University Press, 109-126. 